\title{
TERAJU
}

Teraju: Jurnal Syariah dan Hukum

Volume 01 Nomor 02, September 2019

DOI: $10.35961 /$ teraju.v1i02.61

\section{Sumbangan Sheikh Sa'id Hawwa (1935-1989): Sorotan Awal Proses Tazkiyah Al-Nafs Sebagai Wadah Pembersihan Jiwa}

\author{
Nur Zainatul binti Nadra Zainol \\ Institut Ahli Sunnah wal Jamaah, Universiti Tun Hussein Onn Malaysia \\ nadra@utbm.edu.my
}

\section{Dayangku Zainab binti Pengiran Haji Tuah}

Pusat Ilmu Teras, Kolej Universiti Perguruan Ugama Seri Begawan, Brunei Darussalam rainab.tuah@kupu-sb.edu.bn

\section{Intan Farhana binti Saparuddin}

Jabatan Pengajian Islam, Pusat Pengajian Umum dan Kokurikulum, Universiti Tun Hussein Onn Malaysia

Siti Marpuah

Jabatan Pengajian Islam, Pusat Pengajian Umum dan Kokurikulum, Universiti Tun Hussein Onn Malaysia

\begin{abstract}
Tazkiyah al-nafs is a method of purification of the human soul in the form of internal purification and external formation in order to suppress desires and bad habits that lead to mental health and behavioral disorders. Sufism figures have introduced the method of purification of the soul, including Sheikh Sa'id Hawwa, which further explains Imam alGhazali's method of purification of the soul. This article aims to highlight the contribution of this figure in this field and analyse the approach presented by Sheikh Sa'id Hawwa in the method of tazkiyah al-nafs. This study is a qualitative study with content analysis design. The results show that Sheikh Said Hawwa has highlighted the method of tazkiyah alnafs that is able to educate the human soul to avoid mental health and behavioral disorders. This study can provide early guidance and highlights on the method of purification of the soul based on the Quran and al-sunnah
\end{abstract}

Keywords: Tazkiyah al-nafs, Sufism, Sheikh Sa'id Hawwa 


\section{Pendahuluan}

Sa'id Hawwa merupakan seorang tokoh Islam kontemporari berasal daripada negara Syria. Beliau juga merupakan tokoh terkemuka dalam pertubuhan Ikhwanul Muslimin. Ketokohan beliau telah meletakkan dirianya di antara tokoh-tokoh yang berpengaruh di abad ke 20. Di samping itu, Sa’id juga dikenali sebagai seorang pejuang dalam bidang kesufian. Persoalan tentang jiwa serta kewajipan untuk membersihkan jiwa daripada segala penyakit, menurut Sa'id merupakan langkah yang paling utama perlu dilakukan, bahkan menururt pendapat beliau hukum membersihkan jiwa itu adalah fardhu 'ain bagi setiap Muslim. Pendekatan yang di bawa oleh Sa'id Hawwa adalah untuk membetulkan kekeliruan yang telah dilakukan oleh para sufi tentang konsep perjalanan jiwa menuju Allah SWT. Beliau berpendapat wujud pendekatan sebahagian sufi lebih bersifat jumud antarnya kaedah sulûk (penempuh jalan ruhani) dan pemahaman keislaman masih sempit dan dangkal. Hal ini disebabkan wujud perbezaan yang dalam antara iman secara aqliyah (al-imân al-aqli al-nazhari) dan iman secara rasa (alimân al-syu'ûri al-zawqi).

Namun, kehidupan manusia mempunyai tuntutan yang perlu dilaksanakan. Walaupun secara zahirnya kehidupan itu seolah-olah ada perubahan dari semasa ke semasa namun hakikatnya kehidupan itu mempunyai tuntutan yang sama. Semenjak turunnya Nabi Adam A.S. ke bumi hinggalah ke zuriat terakhir manusia tuntutan untuk beragama tidak ada perubahan walau sedikit pun dan tidak ada pengecualian walau sekelumit pun. Malahan semakin berkembang kehidupan duniawi ini maka mendesak kita kembali kepada agama. Ini bermakna semakin tinggi tamadun keduniaan manusia, maka semakin jauh mereka daripada landasan sebenar. Apabila penyelewengan terhadap tanggungjawab ini berlaku, satu-satunya jalan penyelesaiannya ialah dengan menghidupkan semula fitrah manusia. Ini bukanlah bermakna kita menolak keduniaan. Tetapi meletakannya di tempat yang sesuai baginya. Kembali kepada fitrah manusia iaitu dengan mengenali jiwa dan melakukan proses penyucian jiwa.

\section{Konsep tazkiyah al-nafs}

Sa'id Hawwa merupakan seorang tokoh Islam kontemporari berasal daripada negara Syria. Beliau juga merupakan tokoh terkemuka dalam pertubuhan Ikhwanul

Tazkiyah bermaksud pembersihan atau penyuburan. Dalam konteks ahli tasawuf, tazkiyah merujuk kepada bersih daripada sifat keji dalam diri dan kezaliman lahiriyah (Ibnu Arabi, t.thn: 389). Dalam erti kata yang lain tazkiyah alnafs adalah melibatkan dua proses utama iaitu al-takhalli (التظلي) dan al-tahalli (التطيل). Al-takhalli ialah membersihkan diri daripada sifat-sifat yang buruk kerana ianya adalah najis maknawi yang menghalang untuk sampai kepada hadrat Allah yang Quddus sebagaimana najis yang zahir kepada Allah (al-Qurdi, 1995:457). Manakala al-tahalli pula ialah menghias jiwa dengan sifat-sifat yang mulia sebagaimana yang dituntut oleh Islam. Menurut al-Tusi, al-tahalli ialah mengikut golongan sodiqin sama ada dari sudut perkataan mahupun dalam amalan zahir (Abi Khuzam, 1993:58)

$$
\text { Menurut al-Ghazali (2000), }
$$

Tazkiyah al-Nafs atau penyucian jiwa ini mesti melalui proses Mujabadah al-Nafs dan Riyadah al-Nafs (rujuk Rajah 1 di bawah). Mujahadah al-Nafs ini tidak semudah kata-kata. Ia kadangkala sehingga mengorbankan harta dan diri sendiri. (Muhibbuddin Waly 1994). Al-Ghazali 
(2000) mendefinisikan mujahadah sebagai usaha yang bersungguh-sungguh melawan nafsu atau menghapuskan nafsu syahwat. Riyadah al-Nafs pula bermaksud satu latihan jiwa menuju ke arah kebaikan secara beransur-ansur sehingga sampai ke satu tahap di mana sesuatu yang berat serta payah dilakukan pada awalnya, akhirnya menjadi mudah dan ringan untuk dilakukan (Salasiah 2016).

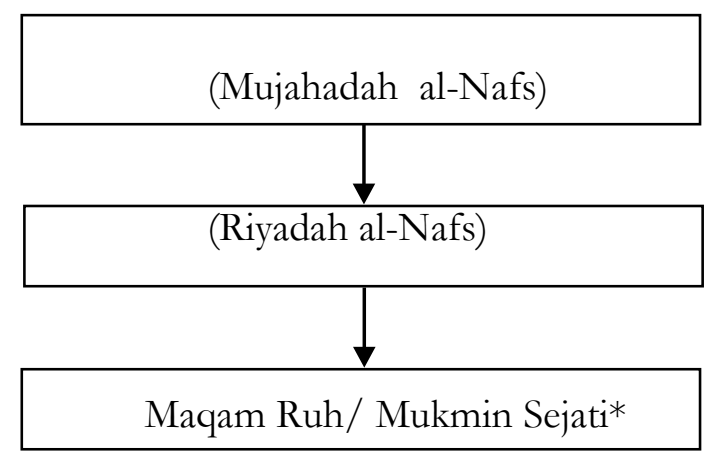

Rajah 1: Proses Tazkiyah al-Nafs

Menurut kajian Salasiah (2008), kaedah al-Ghazali tentang tazkiyah al-Nafs seharusnya diaplikasikan dalam kehidupan masyarakat masa kini yang dipenuhi dengan pelbagai masalah yang kompleks, penyakit-penyakit hati serta kemungkaran akibat kurangnya penghayatan terhadap nilai-nilai agama yang sering menjadikan mereka hilang pertimbangan serta sukar menikmati ketenangan dan kebahagiaan. Lantaran itu, kaedah ini perlu direalisasikan dalam kehidupan masyarakat hari ini supaya masalah mereka dapat diatasi dengan lebih baik. Antara bentukbentuk aplikasi Tazkiyah al-Nafs menurut al-Ghazali ialah mengetahui keburukan sifat marah, dendam dan hasad dengki. Justeru itu, latihan jiwa perlu diberi tumpuan untuk merawat penyakit rohani sehingga mampu menyembuhkan tekanan dan kemurungan melalui sifat sabar, syukur, taubat, ada sikap berharap, takut, ikhlas, berfikir, muhasabah dan mengingati mati.

\section{Metodologi Kajian}

Kajian ini adalah merupakan kajian kualitatif menerusi kaedah pengkajian kepustakaan dan juga dengan reka bentuk analisis kandungan. Pengkaji mengumpul data menerusi metode pensejarahan daripada bahan-bahan yang terdapat di perpustakaan, khususnya data primer tentang Said Hawwa dan juga konsep tazkiyah al-nafs menurut beliau.

\section{Biografi Ringkas Said Hawwa}

Nama lengkapnya adalah Sa'id bin Muhammad Dib bin Mahmud Hawwa An-Nu'aimiy, lebih dikenali dengan gelaran Sa'id Hawwa dan nama panggilannya adalah Abu Muhammad. Beliau telah dilahirkan di kota Hamah, Syria pada tahun 1935. Ibunya telah meninggal dunia ketika beliau berusia 2 tahun. Beliau berpindah ke rumah neneknya di bawah asuhan sang ayah, seorang pejuang pemberani yang berjihad melawan Perancis. Pada zaman remaja telah berkembang pada diri beliau pemikiran sosial, Nasional, ba'ats, dan perjuangan Ikhwanul Muslimin. Penglibatan beliau dalam gerakan Ikhwanul Muslimin, tahun 1952, sewaktu beliau masih pelajar telah menyerlah perjuang beliau terhadap agama Islam.

Sa'id Hawwa berguru dengan beberapa ulama Syria. Antara guru-guru beliau adalah terdiri daripada ulama Hamah seperti Syeikh Muhammad alHamid, Syeikh Muhammad al-Hasyimi, Syeikh Abdul Wahab Dabas, Syeikh Abdul Karim Arrifa'i, Syeikh Ahmad al-Murad dan Syeikh Muhammad Ali Murad. Said Hawwa juga berguru dengan Sheikh Musthafa al-Shiba'i, Mushthafa al-Zarga, Fauzi Faidhullah, dan lain-lain. Pada tahun 1961 beliau lulus dari Universiti Syria, mengikuti kursus ketenteraan pada tahun 1963, berumahtangga pada tahun 1964, dan dikurniakan empat orang anak. 
Di antara karya tulis maupun bukunya yang telah diterbitkan sebagaimana yang telah disebutkan sendiri oleh Sa'id Hawwa dalam bukunya "Hadzihi Tajribati” berikut ini:

Pertama: Silsilah Ushul Tsalatsah, terdapat tiga buku;

1. Allah Jalla Jalaluhu

2. Ar-Rasul ShallAllahu 'alaihi wassallam

3. Al-Islam

Kedua: Silsilah fi al-Manhaj, disusun dalam tiga buku;

1. Al-Asas fi at-Tafsir

2. Al-Asas fi as-Sunnah

3. Al-Asas fi Qawa'id al-Ma'rifah wa dhawabith al-Fahm li an-Nushush

Ketiga: Silsilah al-Fiqhani al-Kabir wa al-

Akbar dalam empat buku;

1. Jaulat fi Fiqhain al-Kabir wa al-Akbar

2. Tarbiyatuna ar-Ruhiyah

3. Al-Mustakhlash fi Tazkiya al-Anfus

4. Mudzakarat fi Manazil ash-Shiddiqin wa ar-Rabbaniyin

Keempat: Silsilah fi al-Banna

1. Jundullah Tsaqafan wa Akhlaqan

2. Min Ajli Khuthwah Ila al-Amam Ala Thariq al-Jihad al-Mubarak

3. Madkhal Ila Da'wah Hasan al-banna rahimahullah

4. Durus fi al-'Amal al-Islami al-Mu'ashir

5. Fushul fi al-Imrah wa al-Amir

6. Fi Afaq at-Ta'lim

7. Hadzihi Tajribati wa Hadzihi Syahadati

8. Rasa'il "Kay La Namdhi Ba'idan 'An Ihtiyajat al-'Ashari, di dalam buku ini terdapat 11 risalah;
a. Munthalaqat Islamiyah Lil Hadharah 'Alamiyah Jadidah
b. Akhlaqiyat wa Sulukiyat Tata'akadu fi al-Qarn al-Khamis 'Asyar al-Hijtiy
c. Falnatadzakar fi 'Ashrina Tsalatsan
d. Ihya ar-Rabbaniyah
e. Al-Ijabat
f. Aqd al-Qarn al-Khamis 'Ashar al- Hijri
g. As-Sirah bi Luqah al-Hub wa asy- Syi'r

h. Al-Khumainiyah Syudzuz fi alAqa'id wa Syudzuz fi al-Mawaqif

i. Ijazah Takhashus ad-Du'at

j. Qawanin al-Bait al-Muslim

k. Ghiza al-Ubudiyah

\section{Konsep Tazkiyah al-Nafs Said Hawwa}

Sikap dan pendirian Sa'id Hawwa dalam hal spiritual dan tasawuf tidak terlepas dari pengaruh iman al-Ghazali, melalui kitabnya Ibya Ulumuddin ${ }^{1}$. hanya saja Sa'id Hawwa mampu mengelaborasikan metode tersebut, dengan elaborasi yang menarik di masanya sehingga dapat dipahami oleh kalangan awam, pelajar, maupun para cendekiawan (Sa'id Hawwa, 1988).

Perbincangan tentang kaedah penyucian jiwa telah dinukilkan dalam karya karangan beliau. Antara perbincangan beliau adalah dalam al-Nafs, dan al-Mustakblas Fi Tarkiyah al-Anfus. Buku ini juga merupakan intisari daripada kitab Ihya Ulumuddin karya al-Ghazali yang disusun semula oleh Sa'id Hawwa (1989) dengan menambah keterangan dan penjelasan yang merujuk kepada sumber al-Quran dan al-Sunnah. Perkara ini dibuktikan apabila beliau berkata:

"Kerana itu dalam buku ini saya hanya akan menyebutkan hal-hal yang memiliki dalil tegas daripada Al-Qur'an dan asSunnah."

Said Hawwa berpandangan ilmu kejiwaan Islam perlu diketengahkan untuk memenuhi keperluan orang Islam kepada aspek kejiwaan bagi mengelakkan

\footnotetext{
${ }^{1} \mathrm{Hal}$ ini dapat diketahui melalui buku-buku yang ia tulis. Dalam Tazkiyat al-nafs misalnya ia menulis tiga buku yang setema dan saling berkaitan iaitu: Tarbiyatuna al-Ruhiyah, buku ini membicarakan berkaitan perjalanan menuju Allah dan selukbeluknya, dimana dalam penjelasannya Said Hawwa banyak memberikan isyarat, menyandarkan, dan menukil pendapat imam alGhazali.
} 
hubungan yang keras dan kasar. Manhaj salafi yang literal dan agak keras dapat dikendurkan pendekatannya dengan ilmu akhlaq kerana dakwah Islam memerlukan kepada akhlaq yang murni. Justeru ilmu ini penting kepada orang Islam dan sebagai pelengkap kepada dakwah itu sendiri. Begitu juga, Manhaj sesetengah ahli sufi yang mungkin terlibat dengan takwil yang sangat jauh perlu dirapatkan agar mereka tidak terlalu jauh. Dengan sumbangan alMarhum, para ulama Saudi mula membuat penulisan di dalam bidang penyucian jiwa. Antara buku mereka yang mendapat sambutan yang hangat ialah $L a$ Tahzan tulisan Sheikh Aid al-Qarni. Sheikh Muaz juga menjelaskan bahawa Sheikh Abd Majid al-Zindani telah mengambil saranan al-Marhum Said Hawwa untuk menekankan aspek kejiwaan sehingga salah satu silibus diajar di Jamiah al-Iman di Sanaah, Yaman. Walau pun orientasi Jamiah al-Iman ini berdasarkan manhaj salafi, tetapi masih menerima aspek tarkizat Al-Nafs.

Kajian tentang pemikiran Sa'id Hawwa berkaitan konsep tazkiyat al-nafs memberikan suatu gambaran bahawa tazkiyat al-nafs sebagai sarana melakukan perjalanan jiwa menuju Allah adalah berperoses pada tiga tahapan; pertama, penyucian (tathahhur) jiwa dari segala penyakit maupun kotoran, kedua, merealisasikan (tahaqquq) berbagai maqam padanya, ketiga, berakhlak (takhalluq) dengan sebagian asma' dan sifat Allah SWT. Dan berakhir pada maqam Ihsan. Sedangkan perjalan jiwa menuju Allah menurut Sa'id Hawwa adalah proses beralihnya jiwa yang kotor dan tercemar menjadi jiwa yang suci lagi tersucikan. Peralihan dari akal non syar'i menuju akal syar'i, dari hati yang kafir menuju hati yang mukmin atau dari hati yang fasik, sakit dan keras menuju hati yang tenang, tentram dan sehat.

Adap kepada Allah berupa pelaksanaan hak-hak-Nya termasuk di dalamnya mengorbankan jiwa dalam rangka jihad di jalan-Nya. Sedangkan adab kepada manusia, sesuai dengan ajaran dan tuntutan maqam dan taklif Ilahi.Jadi tazkiyah memiliki berbagai sarana seperti sholat, infaq, puasa, haji, dzikir, fikir, tilâwah, Alquran, renungan, muhasabah, dan rikir-maut. Dengan demikian jalan menuju perbaikan hati itu hanya dengan ilmu dan amal: berilmu Islam dan beramal Islam, dan zikir menduduki peringkat pertama dalam amal tersebut. Inilah tiga perkara penting: ilmu, amal, dan zikir. Di antara pengaruhnya ialah terhasilnya tauhid, ikhlas, sabar, syukur, cemas, harap, santun, jujur, kepada Allah dan cinta kepada-Nya, di dalam hati. Itulah beberapa bentuk proses perjalanan jiwa menuju Allah.

Said Hawa (1988) mendefiniskan tazkiyah al-nafs secara istilah sebagai pembersihan (tatahhur) daripada penyakit dan kerosakan lalu mencapai/merealisasikan (tahaqquq) tahap-tahap kesucian (maqamat), seterusnya ialah tahap pembentukan sifat (takhalluq), iaitu dengan sifat-sifat terpuji. Beliau juga memperincikan dengan pernyataan bahawa ianya adalah perbuatan membersihkan diri daripada kekotoran, daripada kemahuannya dan syahwatnya yang buruk, dari sifat kebinatangannya, daripada pergolakan dalamannya, serta membersihkannya dari segala bentuk kegelapan.

Setelah diteliti tentang makna perkataan al-nafs yang digunakan, didapati bahawa al-nafs mencakupi dua aspek penting yang ada pada manusia. Pertama: aspek luaran manusia merangkumi fizikal dan derianya. Kedua: aspek dalaman manusia merangkumi mental dan spiritualnya. Maka disimpulkan bahawa tazkiyah al-nafs ialah suatu proses pembaik pulihan dan pendisiplinan diri ke arah yang lebih positif secara dalaman dan luaran menurut acuan agama Islam dengan mengaplikasikan kaedah pembersihan (al- 
takhalli) dan pembentukan (al-tahalli) sehingga mencapai tahap ihsan dan akhlak kenabian

\section{Penutup}

Pendekatan Tazkiyah al-Nafs yang dibawa oleh Sheikh Said Hawwa adalah amat penting dalam kehidupan manusia yang mahu mencari kesejahteraan hidup di dunia mahupun akhirat. Tarkiyah tidak bermaksud menolak perkembangan kehidupan semasa tetapi mengawal kerkembangan hatinya. Tazkiyah al-Nafs membentuk jiwa manusia yang sebenar dengan melakukan segala yang disyariatkan oleh Islam secara istiqamah dengan bimbingan seorang murabbi. Hati dibersihkan daripada sifat yang tercela dan dihias pula dengan sifat yang indah. Tazkiyah perlu melalui pelbagai kaedah di samping hidayah dan taufiq daripada Allah. Hanya manusia yang hatinya suci sahajalah yang dapat kembali kepada Allah dengan sejahtera. Hal ini, merujuk kepada matlamat akhir kaedah dan pendekatan ini adalah menjadi insan yang soleh yang mempunyai kekuatan dalaman (iaitu roh) hasil daripada amalan dan ibadah. Inilah antara rahsia kegemilangan generasi para Sahabat r.a. Umat Islam mesti mengutamakan iman dari nafsu, mempunyai ilmu pengetahuan yang boleh digunapakai dalam semua aspek kehidupan, mengamalkan akhlak-akhlak yang mulia, menjadi "hamba" Allah S.W.T. yang sebenar. Proses penyucian jiwa ini akan menghasilkan ketenteraman, ketenangan dan rasa dekat kepada Allah dengan cara menyucikan hati daripada segala kekotoran dan penyakit dengan membersihkan jiwa dari berbagai jenis penyakit akan secara langsung mendekatkan diri seseorang kepada Allah.]

\section{RUJUKAN}

Che Zarrina \& Sharifah Basirah. 2012. Cadangan Model Psikoterapi Remaja Islam Berasaskan Konsep Tazkiyah al-Nafs. Jurnal Usuluddin, Julai-Disember.

Che Zarrina \& Nor Azlinah. 2016. Terapi Spiritual Melalui Kaedah Tazkiyah al-Nafs oleh Syeikh Abdul Qadir alMandili dalam Kitab Penawar Bagi Hati. Jurnal Afkar, Vol. 18 Special Issue

Hawwa, Sa’id. 1988. Al-Mustakhlis fi Tazkiyah al-Anfus. Dar al-Salam: Kaherah.

Hawwa, Sa'id. 1409 H/1989 M. Mudzakarat Fi Manazil al-Shiddiqun wa al-Rabbaniyin, Bairut: Dar Ammar.

Salasiah. 2008. Pendekatan Da'wah alIrsyad al-Nafsiyy Menurut alGhazali: Satu Kajian di Pusat Kaunseling Majlis Agama Islam Negeri Sembilan. Tesis Doktor Falsafah, Universiti Sains Malaysia.

Salasiah. 2014. Penyucian Jiwa: Pengaruhnya Kepada Keberkesanan Latihan. Konvensyen Latihan Islam Peringkat Kebangsaan Kali Ke-3.

Rajab, K. (2007). al-Maqam dan al-Ahwal dalam Tasawuf. Jurnal Usuluddin, 25, $1-28$. 